mittels Besitz und Wissen, verursachen höhere Kosten in Form von ChipKarten und deren Lesegeräten beim Absender, sowie einen Prüfungsaufwand durch Software auf Seiten des Empfängers. Unabhängig von der Frage, welche Authentisierungsmethode am effizientesten ist, stellt sich die Frage nach den Informationskosten bei einer rein wissensbasierten Authentisierungsmethode. Dabei hat sich gezeigt, dass die Informationskosten des Account-Inhabers keinesfalls gering sind und alleine nicht ausreichen, um Missbrauch zu verhindern.

Neben der höheren Sicherheit durch eine kostenaufwendigere Zwei-Faktor-Authentisierung, kann der Geschäftsgegner auch über einen zweiten, unabhängigen Kommunikationskanal die Information beschaffen. Er kann durch eine Nachfrage beim Account-Inhaber oder durch Bestehen auf Vorleistung in Erfahrung bringen, ob die Willenserklärung vom Namensträger stammt oder mit Vertretungsmacht abgegeben wurde 657

Eine hundertprozentige Sicherheit erreicht er dadurch zwar nicht 658 die Wahrscheinlichkeit steigt jedoch erheblich. Der Aufwand für diese Informationsbeschaffung ist gering. Es kostet den Geschäftsgegner einen kurzen Anruf, einen nachfragenden Brief oder das Warten auf den Geldeingang. Das Gegenteil der ersten ökonomischen Voraussetzung einer Vertrauenshaftung ist somit der Fall. Der Vertrauende hat geringe Informationskosten, wohingegen der Account-Inhaber geringe bis mittlere Informationsbeschaffungskosten hat.

\title{
(2) Produktivität der Information
}

Zweite ökonomische Voraussetzungen für eine Vertrauenshaftung ist die gesamtgesellschaftliche Produktivität derjenigen Informationskosten 659 die für das Vertrauen Ersatz sind ${ }^{660}$ Dabei wird beurteilt, ob der Aufwand zur Beschaffung einer Information geringer ist als der durch die Information bewirkte Nutzen bzw. als der durch eine fehlende Information verursachte

657 Unten Rn. 657

658 Borges, NJW 2011, 2400, 2402.

659 Zur Produktivität von Informationen Hirshleifer, American Economic Review 61 (1971), 561, $563 \mathrm{ff}$.

660 Schäfer/C. Ott ${ }^{5}$, S. 558 f. Dazu auch Cooter/Ulen 6 , S. 357; Fleischer, S. 285; Kötz, in: FS Drobnig, 563, 567; Kötz/Schäfer, S. 175. 
Schaden ${ }^{661}$ Diese Voraussetzung ist der Suche der ökonomischen Analyse nach Allokationseffizienz inhärent. Wenn es mehr Kosten verursacht, die Information zu beschaffen, als die Information an Schaden verhindern kann, ist es unwirtschaftlich den Informationsbeschaffungsaufwand zu betreiben.

646 Zur Verhinderung des Missbrauchs von Zugangsdaten im Internet hat der Account-Inhaber niedrige bis mittelhohe Vermeidungskosten, der Geschäftsgegner hat geringe Informationsbeschaffungskosten. Dem müssen der Nutzen, also die vermiedenen Schäden aus dem Missbrauch der Zugangsdaten im Internet gegenüber gestellt werden. Bei einem Blick auf die eingeklagten Schadenssummen erscheinen die Schäden hoch. Beispielsweise wurde in der $B G H$-Entscheidung „VIP-Bareinrichtung“ eine Summe von gut $€ 32.000$ eingeklagt ${ }^{662}$ Dies entspricht dem positiven Interesse, das der Geschäftsgegner an der Erfüllung des Vertrags hat. Wirtschaftlich betrachtet handelt es sich dabei lediglich um die Expektanz, den erwarteten Gewinn, den der Geschäftsgegner mit dem Vertragsschluss zu machen erwartete. Da der Account-Inhaber am Zustandekommen des Vertrags beim Missbrauch von Zugangsdaten jedoch kein Interesse hat und diesen Vertrag ursprünglich nicht wollte, kann das positive Interesse nicht als Schaden gewertet werden.

647 Vielmehr besteht der Schaden lediglich in Aufwendungen, die der Geschäftsgegner im Vertrauen auf den Vertrag macht, sowie Kosten, die ihm dadurch entstehen, dass er versucht, den vermeintlichen Vertrag durchzusetzen. Im angesprochenen Fall der „VIP-Bareinrichtung“ sind dem Kläger Kosten in Höhe von gut $€ 1.500$ bei der vorgerichtlichen Geltendmachung entstanden sowie nicht näher bezifferte Ausgaben für eine Auskunft über eine ladungsfähige Adresse der Beklagten ${ }^{663}$ In anderen Fällen kann das negative Interesse am Vertrag jedoch das positive übersteigen, beispielsweise wenn die eine Partei in Vorleistung tritt, die Gegenleistung jedoch nicht erhält 664

661 Kötz, in: FS Drobnig, 563, 567 f. Kötz/Schäfer, S. 175 f. Schäfer/C. Ott ${ }^{5}$, S. 574.

$662 B G H$, Urteil v. 11.5.2011, VIII ZR 289/09 (VIP-Bareinrichtung) - BGHZ 189, 346, Rn. 3.

663 Vgl. das Urteil aus der ersten Instanz LG Dortmund, Urteil v. 23. 12. 2008, 3 O 508/08, Rn. 20 f.

664 Wie bei LG Aachen, Urteil v. 15. 12. 2006, 5 S 184/06 - NJW-RR 2007, 565, wo der Kläger den Kaufpreis von rund $€ 650$ bezahlt hat, ohne die gekaufte Ware erhalten zu haben. 